Journal of Animal and Veterinary Advances 10 (3): 307-310, 2011

ISSN: $1680-5593$

(C) Medwell Journals, 2011

\title{
Effect on Pregnancy Rate of a Previously Used Progesterone-Releasing Device and Fixed Time Artificial Insemination in Brahman Cows
}

\author{
${ }^{1} \mathrm{G}$. Martinez, ${ }^{2} \mathrm{P}$. Perez, ${ }^{1} \mathrm{G}$. Torres, ${ }^{1} \mathrm{O}$. Hernandez, ${ }^{3} \mathrm{~J} . \mathrm{J}$. Martinez-Tinajero, \\ ${ }^{4}$ O.D. Montanez-Valdez, ${ }^{1}$ M.E. Ortega-Cerrilla and ${ }^{5}$ R. Rojo-Rubio \\ ${ }^{1}$ Colegio de Postgraduados, Montecillo, Texcoco, Estado de Mexico \\ ${ }^{2}$ Colegio de Postgraduados, Campus Veracruz, Veracruz, Mexico \\ ${ }^{3}$ Facultad de Ciencias Agricolas, Universidad Autonoma de Chiapas, Mexico \\ ${ }^{4}$ Centro Universitario del Sur de la Universidad de Guadalajara, \\ Departamento de Desarrollo Regional, Ciudad Guzman, Jalisco, Mexico \\ ${ }^{5}$ Centro Universitario UAEM Temascaltepec, Universidad Autonoma del Estado de Mexico
}

\begin{abstract}
With the objective to evaluate the efficiency of the Controlled Intravaginal Devices Releasing (CIDR) new and reutilized until a 4th occasion and their effect on the pregnancy rate were studied 594 Brahman multiparous cows with their calves with $468.4 \pm 33.9 \mathrm{~kg}$ of body weight and with a minimum of 90 days postpartum and Fixed Time Artificial Insemination (FTAI) under humid tropical conditions. The cows were randomly assigned to one out to 8 treatments where the CIDR1A was new and anestrous cows; CIDR1C: new and cyclic cows; CIDR2A: Second use and anestrous cows; CIDR2C: Second and cyclic cows; CIDR3A: Third use and anoestrus cows CIDR3C: Third use and cyclic cows; CIDR4A: Fourth use and anestrous cows; CIDR4C: Fourth use and cyclic cows in the following way T1 $(n=116)$ : CIDR1A+estradiol benzoate $(E)+D-$ Cloprostenol+eCG+AI at detected estrus; T2 $(\mathrm{n}=34)$ : CIDR1C $+\mathrm{E}+\mathrm{D}-\mathrm{Cloprostenol}+\mathrm{AI}$ at detected estrus; T3 $(\mathrm{n}=53)$ : CIDR2A+E+D-cloprostenol+eCG+Fixed Time ArtificialInsemination (FTAI); T4 ( $\mathrm{n}=62)$ : CDR2C+E+DCloprostenol+FTAI; T5 $(\mathrm{n}=33)$ : CIDR3A+E+D-Cloprostenol+eCG+FTAI; T6 $(\mathrm{n}=67)$ : CIDR3C+E+DCloprostenol+FTAI; T7 $(\mathrm{n}=41)$ : CIDR4A+E+D-Cloprostenol+eCG+FTAI and T8 $(\mathrm{n}=188)$ : CIDR4C+E+DCloprostenol+FTAI. The pregnancy rate was different among treatments being 35.3, 61.7, 30.1, 64.5, 21.2, 82.0, 41.4 and $48.9 \%$ for T1-T8, respectively. In conclusion, the use of new or reutilized CIDR up to a 4th time plus artificial insemination at fixed time in Brahman cows represents an alternative to synchronize estrus and ovulation to improve gestation percentages.
\end{abstract}

Key words: CIDR, prostaglandins, pregnancy rate, synchronize estrus, gestation, Brahman

\section{INTRODUCTION}

In order to improve the reproductive response in beef cattle females, different techniques have been developed that allow to reinitiate the postpartum ovarian activity within a relatively shorter time than that given by traditional management, nevertheless, the associated high costs does not allow to use them. The use of natural progesterone and progestagens improves ovulation regardless the endocrine environment at the treatment time. To synchronize estrus, it is desirable that females show ovulation in synchrony which would make easy to use artificial insemination at fixed time. There are some evidences that progesterone and estradiol benzoate concentrates estrus clusters during estrus synchronization programs in bovine cattle (Vogg et al.,
2004). In the same way, when eCG is applied at the intrauterine devices removal or subcutaneous implants, synchrony is significantly improved and synchronized estrus are clustered more efficiently without affecting estrus percentage or fertility however, fertility is significantly higher in estrus animals than in acyclic animals. The investigation to evaluate new CIDR has been mentioned by different researchers (Rathbone et al., 2002; Mapletoft et al., 2003). In the last years, different researchers have published investigations with intravaginal devices reused in bovine cattle and ovine.

The intravaginal devices can be reused because the hormonal amount in them is given by grams and the amount that the cows need to be able to show estrus is in nanograms from this form the questioning arises from which the residual concentration of the progestin in the

Corresponding Author: Oziel Dante Montanez Valdez, Departamento de Desarrollo Regional, Centro Universitario del Sur de la Universidad de Guadalajara, Prolongacion Colon S/N, Ciudad Guzman, Jalisco, CP 49000, Mexico 
CIDR is able to induce estrus synchronization with similar rate of gestation when this one is used by second or more occasions. Because of these reasons, the objective of this study was to evaluate the repetitive use of intravaginal devices up to a 4 th time with and without $\mathrm{eCG}$ and its effect on pregnancy rates in Brahman cows.

\section{MATERIALS AND METHODS}

The present study was carried out in the Finca Perseverancia San Jose which is located in Tonala county, Mexico. It is located between $15^{\circ} 51^{\prime} 35^{\prime} ' \mathrm{~N}$ and $93^{\circ} 29^{\prime} 40^{\prime}$ ' $\mathrm{W}$ and the average altitude is $30 \mathrm{~m}$ above sea level. The climate is warm-humid with a rainy season during summer and a drought season from February-June when the pasture consumption decreases significantly. A total of 594 multiparous Brahman cows with their calves and average weight of $468.4 \pm 33.9 \mathrm{~kg}$ were used for this study. Transrectal palpation was done at day 90 postpartum and in this moment cows were assigned like cyclic or acyclic.

Cows were inseminated $12 \mathrm{~h}$ after the detection of the estrus in T1 and T2. Females from T3-T8 were artificially inseminated at fixed time $30 \mathrm{~h}$ after the 2nd injection of estradiol benzoate and/or eCG with frozen semen of tested fertility from different bulls. Artificial inseminations were made by the same technician. Pregnancy was determined 50 days post insemination by rectal examination. Cows were individually identified with ear tags and treated against ecto and endo-parasites as well as vaccinated against clostridiasis, anthrax, pasteurellosis, rabies and brucellosis. Cows were under continuous lactation and their calves remained with them until weaning. The corporal condition index ranged 3-4 in a 1-5 scale where one represents an emaciated cow and five represents an obese cow (Edmonson et al., 1989). Cows grazed freely on stargrass (Cynodon plectostachyus) and Jaragua grass (Hyparrhenia rufa) pasturelands.

A randomly unbalanced design with eight treatments and different number of replications was used. Each replication was represented by a cow and her calf in a factorial arrangement $2 \times 4$ where factors were cyclic and acyclic cows. The cows were randomly assigned to one out to 8 treatments where the CIDR1A was: new and anestrous cows; CIDR1C: new and cyclic cows; CIDR2A: Second use and anestrous cows; CIDR2C: Second and cyclic cows; CIDR3A: Third use and anoestrus cows; CIDR3C: Third use and cyclic cows; CIDR4A: Fourth use and anestrous cows; CIDR4C: Fourth use and cyclic cows, in the following way: $\mathrm{T} 1 \quad(\mathrm{n}=116)$ : CIDR1A+estradiol benzoate (E)+D-Cloprostenol+eCG+AI at detected estrus; T2 $(\mathrm{n}=34)$ : CIDR1C+E+D-
Cloprostenol $+\mathrm{AI}$ at detected estrus; $\mathrm{T} 3(\mathrm{n}=53)$ : $\mathrm{CIDR} 2 \mathrm{~A}+$ $\mathrm{E}+\mathrm{D}-$ Cloprostenol $+\mathrm{eCG}+$ Fixed Time Artificial Insemination (FTAI); T4 ( $\mathrm{n}=62$ ): CIDR2C+E+D-Cloprostenol+FTAI; T5 $(\mathrm{n}=33):$ CIDR3A+E+D-Cloprostenol+eCG+FTAI; T6 $(\mathrm{n}=67)$ : CIDR3C+E+D-Cloprostenol+FTAI; T7 $(\mathrm{n}=41)$ : CDR4A+E+D-Cloprostenol + eCG+FTAI and T8 $(\mathrm{n}=188)$ : CIDR4C+E+D-Cloprostenol+FTAI. Data were analyzed through, the free distribution $\chi^{2}$ non-parametric test.

\section{RESULTS AND DISCUSSION}

The estrus percentages showed after CIDR removals were 61.2 and $79.4 \%$ for $\mathrm{T} 1$ and $\mathrm{T} 2$, respectively. The mean interval from CIDR withdrawal to onset of estrus was $44.6 \pm 15.6$ and $42.2 \pm 12.1 \mathrm{~h}$ for the $\mathrm{T} 1$ and $\mathrm{T} 2$ treatments, respectively. None of these differences were significant as shown in Table 1. The estrus response and distribution of $\mathrm{T} 1$ and $\mathrm{T} 2$ groups are shown in Fig. 1. The pregnancy rates at day 50 following estrus synchronization in overall of experimental groups are shown in Table 2. These results are similar to those reported by Diaz registered $70 \%$ of estrus when synchronizing Brahman cows through natural progesterone and estradiol benzoate in tropical

Table 1: Response of acyclic and cyclic Brahman cows to estrus synchronization with CIDR used for first time plus estradiol benzoate, D-cloprostenol, equine chorionic gonadotrophin and artificial insemination at detected estrus

\begin{tabular}{lll}
\hline & \multicolumn{1}{c}{ Treatments $^{1}$} & \\
Results & T1 & T2 \\
\hline Estrus $(\%)$ & 61.2 & 79.4 \\
Onset of estrus $(\mathrm{h})$ & $44.6 \pm 15.6$ & $42.2 \pm 12.1$ \\
\hline${ }^{1} \mathrm{~T} 1(\mathrm{n}=116):$ CIDR1A+estradiol benzoate $(\mathrm{E})+\mathrm{D}-\mathrm{Cloprostenol+eCG+AI}$ \\
at detected estrus; T2 $(\mathrm{n}=34):$ CIDR1C+E+D-Cloprostenol+AI at detected \\
estrus
\end{tabular}

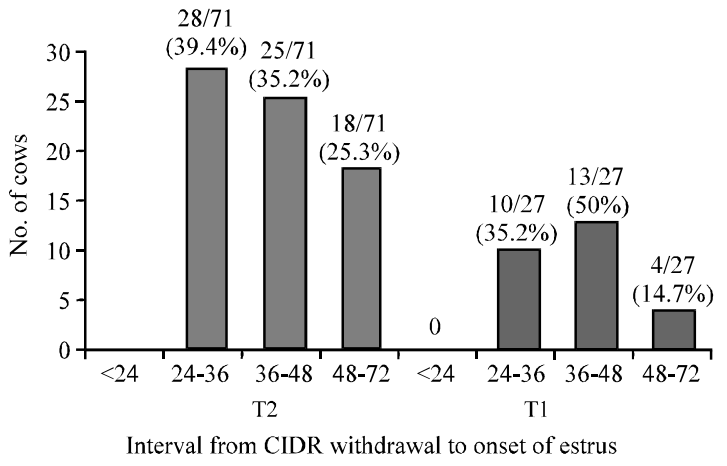

Fig. 1: Distribution of the onset of estrus after synchronization in Brahman cows. T1 $(n=116)$ : CIDR1A+estradiol benzoate (E)+D-Cloprostenol $+\mathrm{eCG}+\mathrm{AI}$ at detected estrus; $\mathrm{T} 2(\mathrm{n}=34)$ : $\mathrm{CDR} 1 \mathrm{C}+$ $\mathrm{E}+\mathrm{D}-\mathrm{Cloprostenol}+\mathrm{AI}$ at detected estrus 
Table 2: Pregnancy rate of cows synchronized at estrus with CIDR reused up to a fourth time with and without $\mathrm{eCG}$

\begin{tabular}{lccc}
\hline Treatment group1 & Cows $(\mathrm{n})$ & Pregnant & Pregnancy rate $(\%)$ \\
\hline CIDR1A & 116 & 41 & $35.3^{\mathrm{a}}$ \\
CIDR1C & 34 & 21 & $61.7^{\mathrm{b}}$ \\
CIDR2A & 53 & 16 & $30.1^{\mathrm{bc}}$ \\
CIDR2C & 62 & 40 & $64.5^{\mathrm{c}}$ \\
CIDR3A & 33 & 7 & $21.2^{\text {cd }}$ \\
CIDR3C & 67 & 55 & $82.0^{\mathrm{d}}$ \\
CIDR4A & 41 & 17 & $41.4^{\mathrm{d}}$ \\
CIDR4C & 188 & 92 & $48.9^{\mathrm{d}}$ \\
\hline
\end{tabular}

${ }^{1} \mathrm{~T} 1(\mathrm{n}=116)$ : CIDR1A+estradiol benzoate (E)+D-Cloprostenol+eCG+AI at detected estrus; $\mathrm{T} 2(\mathrm{n}=34)$ : CIDR1C+E+D-Cloprostenol+AI at detected estrus; T3 ( $\mathrm{n}=53$ ): CIDR2A+E+D-Cloprostenol+eCG+Fixed Time Artificial Insemination (FTAI); T4 $(n=62)$ : CIDR2C+E+D-Cloprostenol +FTAI; T5 (n = 33): CIDR3A+E+D-Cloprostenol+eCG+FTAI; T6 $(\mathrm{n}=67)$ : CIDR3C+E+D-Cloprostenol+FTAI; T7 $(n=41)$ : CIDR4A+E+DCloprostenol+eCG+FTAI and T8 $(n=188)$ : CIDR4C+E+D-Cloprostenol+ FTAI

conditions. These results coincide with results published by different researchers (Penny et al., 2000; Lucy et al., 2001) they observed that by administrating progesterone plus estradiol benzoate and eCG, estrus is synchronized and ovulation is induced. By using eCG in anestrous cows ovulation are induced allowing to inseminate cows without estrus symptoms or anestrous cows and getting good conception indexes.

Contrarily, the inductions of estrus with estradiol benzoate not always induce ovulation. Estrus expression is a critical factor in conventional artificial insemination programs (Vogg et al., 2004) nevertheless in this study FTAI was used to avoid low pregnancy percentages owing to estrus detection potential failure. This study found that Brahman cows had an average pregnancy percentage of $48.1 \%$ at synchronized estrus being of 35.3 , $61.7,30.1,64.5,21.2,82.0,41.4$ and $48.9 \%$ from T1-T8, respectively there were differences $(\mathrm{p}<0.05)$ among treatments (Table 2). As can be observed in the results, cyclic cows showed a better reproductive response than anestrous cows being $64.2 \%$ the pregnancy percent for cyclic cows and $32 \%$ for the anestrous cows.

The obtained pregnancy percentage in all groups falls within the range cited by other studies (35.1-71.4\%; Perez-Hernandez et al., 2002). Similarly, it coincides with other studies carried out in tropical regions even though it was realized during the rainy season which implies a higher forage quality and availability. However, it has been reported that the presence of males affects the resumption of postpartum ovarian activity in Bos indicus cattle. Because in tropical regions seasons are not well defined, sometimes it is impossible to differentiate among them however, it is important to point out that in the study area there are two well defined seasons (rainy and drought) which could potentially affect the cycles depending on forage availability. These results are better than those reported by Solorzano who used CIDR 2 times and found pregnancy percentages of $42.1,37.1$ and $36.1 \%$ with new, first and second use CIDR correspondingly. In the same way, Larocca obtained $64 \%$ of pregnancy using Norgestomet $+\mathrm{E}+$ Delprostenate $+\mathrm{eCG}$ and AI $12 \mathrm{~h}$ after estrus detection in Holstein cows under tropical conditions in Costa Rica. Other researchers obtained 51\% of pregnancies when using subcutaneous implants of norgestomet combined with eCG; this result is lower than results of $\mathrm{T} 6$ where we used $\mathrm{CIDR}+\mathrm{E}+\mathrm{D}$-Cloprostenol+ eCG+FTAI.

These results confirm findings reported by Yavas and Walton (2000) they affirm that by using progestagens to induce the first postpartum ovulation, a corpus luteum is produced with normal duration in response to the combined injection of eCG causing a fertile estrus. Similarly, paludo infer that the first dominant follicles detected during the third postpartum week ovulate in response to hormonal treatments and they can be used as precursors for reestablishing from postpartum anestrous. According to Cavestany this study reaffirms that cows have greater opportunity of being pregnant if they had a normal estrus cycle before. In the Brahman race as well as in other zebu races, the postpartum ovarian activity resumption is the most important factor into the partum-conception interval.

This variable determines the profitability of bovine livestock exploitations. Perez-Hernandez et al. (2002) mentioned that suckling is a very important factor involved in the delayed ovarian activity resumption because it affects the interval partum-first ovulation in cows. In the interval partum-conception it is necessary to consider those factors affecting the herd fertility like semen quality, AI technique, embryo mortality and the AI time related to ovulation (Lucy et al., 1992).

The corporal condition has a significant effect on the reproductive response in artificially inseminated females. Corporal condition of the cows of this study was 3 in a one to five scale where one was extremely skinny cows and 5 represented obese cows. In a other study heifers with good corporal condition had a larger pregnancy percentage ( $79.1 \%$ ) compared with those heifers with poor corporal condition (36.4\%). In other study, a similar effect was found in acyclic lactating and in poor physical conditions cows where only $26 \%$ of them got pregnant. Moreover, a physiological mechanism avoiding cows getting pregnant if they loss $>25-30 \%$ of their weight during the postpartum period had been considered as a factor limiting the reproductive efficiency in postpartum cows (Oliver and Richardson, 1976). Under these considerations, one of the factors that have contributed largely too little diffusion of AI is the deficiency in estrus detection particularly in zebu cows. 


\section{CONCLUSION}

The use of new or reutilized CIDR up to a 4th time plus fixed time artificial insemination in Brahman cows represents an alternative to synchronize estrus and ovulation to improve gestation percentages under tropical conditions of Mexico.

\section{REFERENCES}

Edmonson, A.J., I.J. Lean, L.D. Weaver, T. Farver and G. Webster, 1989. A body condition scoring chart for Holstein dairy cows. J. Dairy Sci., 72: 68-78.

Lucy, M.C., H.J. Billings, W.R. Butler, L.R. Ehnis and M.J. Fields et al., 2001. Efficacy of an intravaginal progesterone insert and an injection of PGF2á for synchronizing oestrus and shortening the interval to pregnancy in postpartum beef cows, peripubertal beef heifers and dairy heifers. J. Anim. Sci., 79: 982-995.

Lucy, M.C., J. Beck, C.R. Staples, H.H. Head, R.L. De la Sota and W.W. Thatcher, 1992. Follicular dynamics, plasma metabolites, hormones and insulinlike growth factor (IGF-I) in lactating cows with positive or negative energy balance during the preovulatory period. Reprod. Nutr. Dev., 32: 331-341.

Mapletoft, R.J., M.F. Martínez, M.G. Colazo and J.P. Kastelic, 2003. The use of controlled internal drug release devices for the regulation of bovine reproduction. J. Anim Sci., 81: E28-E36.
Oliver, J. and F.D. Richardson, 1976. Relationship between conception rate in beef cattle and weight change. Proceedings of the Beef Cattle Production in Developing Countries, (BFCPDC'76), Edinburgh, UK., pp: 154-157.

Penny, C.D., B.G. Lowman, N.A. Scott and P.R. Scott, 2000. Repeated estrus synchronization of beef cows with progesterone implants and the effects of a gonadotrophin-releasing hormone agonist at implant insertion. Vet. Rec., 146: 395-398.

Perez-Hernandez, P., M. Garcia-Winder and J. GallegosSanchez, 2002. Postpartum anoestrus is reduced by increasing the within-day milking to suckling interval in dual purpose cows. Anim. Reprod. Sci., 73: 159-168.

Rathbone, M.J., C.R. Bunt, C.R. Ogle, S. Burggraaf, K.L. Macmillan, C.R. Burke and K.L. Pickering, 2002. Reengineering of a commercially available bovine intravaginal insert (CIDR insert) containing progesterone. J. Control. Release, 85: 105-115.

Vogg, G., S.C.J. Hoff, C.M. Jaume and M.J.C. Ferrugem, 2004. The effect of estradiol benzoate after progestagen supplementation for estrus synchronization in beef heifers. Acta Sci. Vet., 32: $41-46$.

Yavas, Y. and J.S. Walton, 2000. Induction of ovulation in postpartum suckled beef cows: A review. Theriogenol., 54: 1-23. 